\title{
Impact of aerobic exercise versus resisted exercise on endothelial activation markers and inflammatory cytokines among elderly
}

\author{
Shehab M Abd El-Kader ${ }^{1}$, Fadwa M Al-Shreef ${ }^{2}$, Osama H Al-Jiffri ${ }^{2}$
}

1. Department of Physical Therapy, Faculty of Applied Medical Sciences, King Abdulaziz University, Jeddah, Saudi Arabia.

2. Department of Medical Laboratory Technology, Faculty of Applied Medical Sciences, King Abdulaziz

University, Jeddah, Saudi Arabia.

\begin{abstract}
Background: Aging is the major risk factor for the development of cardiovascular diseases as aging increases plasma levels of pro-inflammatory mediators and endothelial dysfunction. Physical exercise is a potential strategy for improving the endothelial dysfunction and chronic inflammation that accompanies aging. However, there is a need to differentiate between aerobic and resistance exercise training regarding endothelial activation markers and systemic inflammation among elderly population.

Objective: The aim of this study was to compare the impact of six months of aerobic versus resisted exercise training on inflammatory cytokines and endothelial activation markers among elderly.

Material and methods: Eighty previously sedentary elderly subjects participated in this study, their age ranged from 61-66 years. All subjects were randomly assigned to supervised aerobic exercise intervention group (group A, $\mathrm{n}=40$ ) or resistance exercise group (group B, $\mathrm{n}=40$ ).

Results: The mean value of interleukin-10 (IL-10) was significantly increased, where the mean value of inter-cellular adhesion molecule (ICAM-1), vascular cell adhesion molecule (VCAM-1), E-selectin, tumor necrosis factor alpha (TNF- $\alpha$ ) and interleukin-6 (IL-6) were significantly decreased in group (A) and group (B). In addition, there were significant differences in the mean levels of the investigated parameters between group (A) and group (B) at the end of the study.

Conclusion: The current study provides evidence that aerobic exercise is more appropriate in modulate entering altered endothelial activation and inflammatory markers than resisted exercise among elderly population.

Keywords: Endothelial activation markers; inflammatory cytokines; aerobic exercise; resistance exercise; aging.

DOI: https://dx.doi.org/10.4314/ahs.v19i4.9

Cite as: Abd El-Kader SM, Al-Shreef FM, Al-Jiffri OH. Impact of aerobic exercise versus resisted exercise on endothelial activation markers and inflammatory cytokines among elderly. Afri Health Sci. 2019;19(4):2874-2880. bttps:/ / dx.doi.org/10.4314/abs.v19i4.9
\end{abstract}

\section{Introduction}

Aging is associated with evident changes in the cardiovascular system that reflect alterations of biochemical adaptive mechanisms ${ }^{1,2}$ as aging is associated with endothelial dysfunction and low systemic inflammation where the cytokines levels are usually elevated ${ }^{3,4}$. Inflammation is considered to have a role in disease development \& prognosis ${ }^{5}$, and high levels of inflammatory markers in-

\section{Corresponding author: \\ Shehab M Abd El-Kader, \\ Department of Physical Therapy, \\ Faculty of Applied Medical Sciences, \\ King Abdulaziz University, \\ P.O. Box 80324, Jeddah, 21589, Saudi Arabia. \\ Email: salmuzain@kau.edu.sa}

duce an increased risk for development of cancer and cardiovascular diseases ${ }^{6,7}$.

Aerobic exercise training may significantly lower blood pressure in older hypertensive individuals, improving endothelial function and vascular tone ${ }^{8}$. In particular, swimming exercise has been shown to elicit hypotensive effects and improvements in vascular function in previously sedentary older adults ${ }^{9}$. However, aerobic and resistance exercise can improve the functional capacity among elderly population ${ }^{10,11}$. Aerobic and resistance exercises training has been recommended as an anti-inflammatory therapy ${ }^{12-14}$.

It has been suggested that exercise is associated with an improvement in endothelial function, arterial wall properties and healthy status, with a parallel reduction in sys- 
tolic blood pressure, inflammatory process, and oxidative stress $^{15-17}$. Regular aerobic exercise can slow down the age-related losses in endothelial function ${ }^{18}$.

As there is limitation in studies reporting the differences between the benefits of aerobic exercise and resistance exercise upon endothelial activation markers and systemic inflammation among elderly Saudi subjects. This study was an intention to compare the influence of six months of aerobic exercise and resisted exercise upon endothelial activation markers and immune system response among elderly.

\section{Patients and methods}

\section{Subjects}

Eighty sedentary Saudi elderly volunteers; their age ranged from 61 to 67 year, recruited from the community. They were considered sedentary if they had not performed exercise of 15 minutes duration more than two times per week for the previous six months. Exclusion criteria included smoking, cancer, arthritis, immune disorders, taking medications that affect immune function (i.e. aspirin, anti-inflammatory drugs and anti-depressants), recent surgery, infection and vaccination. Participants were randomized to either an aerobic exercise group (group A) or resistance exercise group (group B). Both groups participated in the exercise intervention conducted three times per week for six months (starting in April-June and ending in October-December, 2017). Exercise sessions were supervised and monitored by trained exercise specialists. Infored consent was obtained from all participants. This study was approved by the Scientific Research Ethical Committee, Faculty of Applied Medical Sciences at King University.

\section{Measurements}

The following measurements were taken before the study and after six months at the end of the study.

A. Inflammatory cytokines: Blood samples were drained from the antecubital vein after a 12-hour fasting, the blood samples were centrifuged at $+4{ }^{\circ} \mathrm{C}(1000=\mathrm{g}$ for 10 min). "Immulite 2000” immunassay analyzer (Siemens Healthcare Diagnostics, Deerfield, USA) analyzed Interleukin-6 (IL-6) and Interleukin-10 (IL-10) levels. However, tumor necrosis factor-alpha (TNF- $\alpha$ ) was measured by ELISA kits (ELX 50) in addition to ELISA microplate reader (ELX 808; BioTek Instruments, USA); intra-assay coefficients of variation was less than $3.5 \%$ for all measurements.

B. Determination of endothelial activation markers: The serum samples were stored at $-80{ }^{\circ} \mathrm{C}$ to be used by the enzyme-linked immunosorbent assays (ELISAs) in order to measure levels of ICAM-1 and VCAM-1, E-selectin, (R\&D Systems).

\section{Procedures}

A. Aerobic exercise training program: Patients in group (A) were enrolled in aerobic exercise training sessions on a treadmill (the initial, 5-minute warm-up phase performed on the treadmill at a low load, each training session lasted 30 minutes and ended with 5-minute recovery and relaxation phase) either walking or running, based on heart rate, until the target heart rate was reached, according to American College of Sport Medicine guidelines. The program started with 10 minutes of stretching and was conducted using the maximal heart rate index (HR$\max )$ estimated by 220 -age. First 3 months $=60-70 \%$ of $\mathrm{HR}_{\max }$, second 3 months $=70-80 \%$ of $\mathrm{HRmax}^{19}$.

B. Resistance exercise training: Patients of group (B) were enrolled in resistance exercise training sessions. The program started with 10 minutes of stretching and was conducted with exercises done on nine resistance machines. The resistance machines used were: chest press, bicep curl, triceps extension, lower back, abdominals, leg press, leg curl and leg extension. Subjects performed three sets of 8-12 repetitions, with 60 seconds of rest between each set. Resistance was increased by five pounds after the subject was able to complete three sets of eight repetitions on three consecutive days. Subjects were trained using between 60 and $80 \%$ of their one maximal repetition weight $(1-\mathrm{RM})^{20}$.

\section{Statistical analysis}

The mean values of the investigated parameters obtained before and after six months in both groups were compared using paired " $t$ " test. Independent " $t$ " test was used for the comparison between the two groups $(\mathrm{P}<0.05)$.

\section{Results}

The two groups were considered homogeneous regarding the demographic variables (figure 1). The mean age of group, (A) was $64.28 \pm 3.61$ year, and the mean age of group (B) was $63.98 \pm 3.27$ year. 


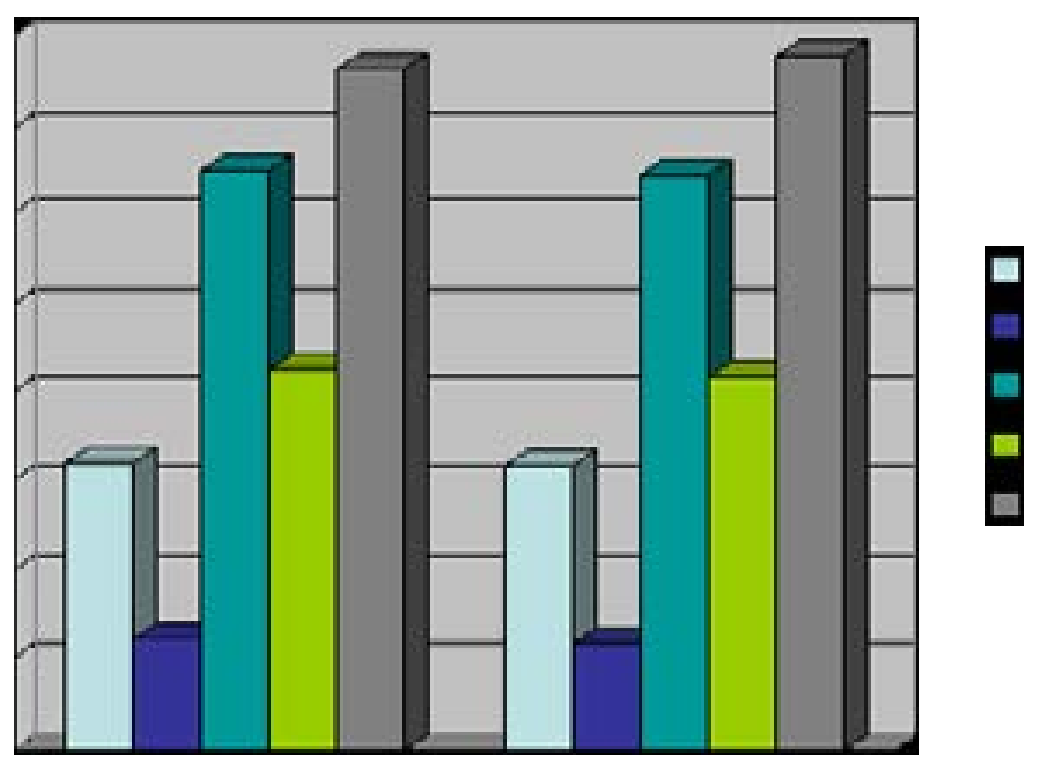

Figure (1): Baseline characteristics of study participants.

There were no significant differences in age, weight, where the mean value of ICAM-1, VCAM-1, E-selectin, height, body mass index (BMI), systolic blood pressure, IL- 6 and TNF- $\alpha$ were significantly decreased in group (A) diastolic blood pressure and maximal heart rate (HRmax) and group (B) (table 1\&2). In addition, there were signifbetween the two groups.

The mean value of IL-10 was significantly increased, icant differences between mean levels of the investigated parameters of group (A) and group (B) at the end of the study (table 3).

Table (1): Mean value and significance of TNF- $\alpha$, IL-6, IL-10, ICAM-1, VCAM-1 and Eselectin of group (A) before and at the end of the study.

\begin{tabular}{|l|l|l|l|c|}
\hline & \multicolumn{2}{|c|}{ Mean + SD } & \multirow{2}{*}{$\begin{array}{c}\text { t- } \\
\text { value }\end{array}$} & \multirow{2}{*}{ Significance } \\
\cline { 2 - 4 } & Pre & Post & 6.18 & $\mathrm{P}<0.05$ \\
\hline TNF- $\boldsymbol{\alpha}(\mathrm{pg} / \mathrm{mL})$ & $4.95 \pm 1.74^{*}$ & $3.12 \pm 1.45$ & 6.75 & $\mathrm{P}<0.05$ \\
\hline IL-6 $(\mathrm{pg} / \mathrm{mL})$ & $2.71 \pm 0.98^{*}$ & $1.63 \pm 0.79$ & 5.75 & $\mathrm{P}<0.05$ \\
\hline IL-10 $(\mathrm{pg} / \mathrm{ml})$ & $5.84 \pm 1.35^{*}$ & $7.75 \pm 1.28$ & 6.42 & $\mathrm{P}<0.05$ \\
\hline ICAM-1 $(\mathrm{ng} / \mathrm{ml})$ & $15.17 \pm 3.42^{*}$ & $12.18 \pm 3.26$ & 7.25 & $\mathrm{P}<0.05$ \\
\hline VCAM-1 $(\mathrm{ng} / \mathrm{ml})$ & $16.65 \pm 4.18^{*}$ & $11.29 \pm 3.17$ & 7.44 & $\mathrm{P}<0.05$ \\
\hline E-selectin $(\mathrm{ng} / \mathrm{ml})$ & $4.62 \pm 1.24^{*}$ & $2.15 \pm 0.93$ & 6.13 & \\
\hline
\end{tabular}

TNF- $\alpha$ : tumor necrosis factor - alpha; IL-6: Interleukin-6; IL-10: Interleukin-10; ICAM-1: Intercellular adhesion molecule; VCAM-1: Vascular cell adhesion molecule; $(*)$ indicates a significant difference between the two groups, $\mathrm{P}<0.05$. 
Table (2): Mean value and significance of TNF- $\alpha$, IL-6, IL-10, ICAM-1, VCAM-1 and Eselectin of group (B) before and at the end of the study.

\begin{tabular}{|l|l|l|c|c|}
\hline & \multicolumn{2}{|c|}{ Mean + SD } & \multirow{2}{*}{$\begin{array}{c}\text { t- } \\
\text { value }\end{array}$} & \multirow{2}{*}{ Significance } \\
\cline { 2 - 4 } & \multicolumn{1}{|c|}{ Pre } & \multicolumn{1}{|c|}{ Post } & 3.17 & $\mathrm{P}<0.05$ \\
\hline TNF- $\boldsymbol{\alpha}(\mathrm{pg} / \mathrm{mL})$ & $4.70 \pm 1.82^{*}$ & $3.84 \pm 1.64$ & 3.14 & $\mathrm{P}<0.05$ \\
\hline IL-6 $(\mathrm{pg} / \mathrm{mL})$ & $2.63 \pm 0.87^{*}$ & $2.17 \pm 0.81$ & 3.28 & $\mathrm{P}<0.05$ \\
\hline IL-10 $(\mathrm{pg} / \mathrm{ml})$ & $6.17 \pm 1.29^{*}$ & $7.14 \pm 1.34$ & 3.56 & $\mathrm{P}<0.05$ \\
\hline ICAM-1 $(\mathrm{ng} / \mathrm{ml})$ & $14.93 \pm 3.65^{*}$ & $13.53 \pm 3.27$ & 3.64 & $\mathrm{P}<0.05$ \\
\hline VCAM-1 $(\mathrm{ng} / \mathrm{ml})$ & $16.28 \pm 4.25^{*}$ & $13.71 \pm 3.92$ & 3.15 & $\mathrm{P}<0.05$ \\
\hline E-selectin $(\mathrm{ng} / \mathrm{ml})$ & $4.53 \pm 1.19^{*}$ & $3.27 \pm 0.98$ & 3.05 \\
\hline
\end{tabular}

TNF- $\alpha$ : tumor necrosis factor - alpha; IL-6: Interleukin-6; IL-10: Interleukin-10; ICAM-1: Intercellular adhesion molecule; VCAM-1: Vascular cell adhesion molecule; $\left({ }^{*}\right)$ indicates a significant difference between the two groups, $\mathrm{P}<0.05$.

Table (3): Mean value and significance of TNF- $\alpha$, IL-6, IL-10, ICAM-1, VCAM-1 and Eselectin in group (A) and group (B) at the end of the study.

\begin{tabular}{|l|c|l|c|c|}
\hline & \multicolumn{2}{|c|}{ Mean + SD } & \multirow{2}{*}{$\begin{array}{c}\text { t- } \\
\text { value }\end{array}$} & \multirow{2}{*}{ Significance } \\
\cline { 2 - 4 } & Group (A) & \multicolumn{1}{|c|}{ Group (B) } & \\
\hline TNF- $\boldsymbol{\alpha}(\mathrm{pg} / \mathrm{mL})$ & $3.12 \pm 1.45^{*}$ & $3.84 \pm 1.64$ & 3.23 & $\mathrm{P}<0.05$ \\
\hline IL-6 $(\mathrm{pg} / \mathrm{mL})$ & $1.63 \pm 0.79^{*}$ & $2.17 \pm 0.81$ & 3.35 & $\mathrm{P}<0.05$ \\
\hline IL-10 $(\mathrm{pg} / \mathrm{ml})$ & $7.75 \pm 1.28^{*}$ & $7.14 \pm 1.34$ & 3.51 & $\mathrm{P}<0.05$ \\
\hline ICAM-1 $(\mathrm{ng} / \mathrm{ml})$ & $12.18 \pm 3.26^{*}$ & $13.53 \pm 3.27$ & 3.72 & $\mathrm{P}<0.05$ \\
\hline VCAM-1 $(\mathrm{ng} / \mathrm{ml})$ & $11.29 \pm 3.17^{*}$ & $13.71 \pm 3.92$ & 3.93 & $\mathrm{P}<0.05$ \\
\hline E-selectin $(\mathrm{ng} / \mathrm{ml})$ & $2.15 \pm 0.93^{*}$ & $3.27 \pm 0.98$ & 3.11 & $\mathrm{P}<0.05$ \\
\hline
\end{tabular}

\section{Discussion}

Aging is associated with increased cardiovascular risk, systemic inflammation and endothelial dysfunction ${ }^{21,22}$. To the best of our knowledge, this is the first comparative study between aerobic and resistance exercises addressing inflammatory and endothelial activation markers among elderly subjects after six months of exercise training.

Our results demonstrated that both aerobic and resistance exercise training resulted in reduction in the mean values of TNF- $\alpha$, IL- 6 and CRP, in addition to elevation in the mean value of IL-10 which suggested that exercise training could modulate systemic inflammation biomarkers in elderly individuals with more significant changes following aerobic exercise training. Several studies have shown that moderate physical exercise promotes the modulation of inflammation ${ }^{23-25}$. Several large cohort studies have found a relationship between self-reported physical activity levels and systemic markers of inflammation: higher levels of physical activity are coupled to lower levels of circulating inflammatory markers in elderly individuals ${ }^{26-28}$. Regarding the aerobic exercise training, our results agreed with Nicklas et al. showed that regular aerobic exercise training was efficient in lowering IL-6 levels even without weight $\operatorname{loss}^{29}$. While, Santos and colleagues proved that moderate aerobic exercise training for $60 \mathrm{~min} /$ day, 3 days/week for six months can improve sleep in the elderly via anti-inflammatory effect of 
aerobic training ${ }^{30}$. However, Kohut et al. reported that 10-months of aerobic, but not resistance exercise, significantly reduced serum inflammatory mediators in older adults ${ }^{31}$. Similarly, Bote et al. demonstrated that eight months of aquatic-based exercise training tempered neutrophil activation and decreased systemic levels of IL-8 and noradrenalin compared to controls ${ }^{32}$. In the other hand, our results regarding resistance exercise training agreed with White et al. found alterations in the biomarkers of inflammation after 8 weeks of resistance training in individuals with multiple sclerosis ${ }^{33}$. Where, Prestes et al. performed a resistance training for 16 weeks in elderly sedentary and found reductions in the levels of IL- 6 after training ${ }^{34}$. Moreover, our results confirmed that aerobic exercise training is more appropriate to modify the inflammatory markers among elderly and these agreed with Ploeger et al. reported that moderate aerobic exercise training has been recommended as an anti-inflammatory therapy ${ }^{35}$.

The three possible mecha $\neg$ nisms of exercise anti-inflammatory effects include reduction in visceral fat mass $^{36}$, reduction in the circulating numbers of pro-inflammatory monocytes ${ }^{37}$ and an increase in the circulating numbers of regulatory $\mathrm{T}$ cells ${ }^{38}$. Moreover, Hong and colleagues show that cardiorespiratory fitness is associated with reduced low grade inflammation that may in part be mediated by enhancing the ability of immune cells to suppress inflammatory responses via adrenergic receptors ${ }^{39}$.

Our results demonstrated that aerobic exercise training resulted in greater significant reduction in the mean values of ICAM-1, VCAM-1 and E-selectin than resistance exercise training. These findings agreed with Yang and colleagues investigated exercise effects on the vascular function in hypercholesterolemia, male New Zealand white rabbits proved that animals of exercise groups who ran on a treadmill at $0.88 \mathrm{~km} / \mathrm{h}$ for 10-60 min/day, 5 day/ week, and 8 weeks in total resulted in reduction in the expression of adhesion molecules and ameliorates the severe vascular dysfunction induced by high cholesterol feeding ${ }^{40}$. While, Zoppini and colleagues proved that a twice-weekly, 6-month, progressive aerobic-training program, without a concomitant weight loss diet, is associated with significant decreases in circulating P-selectin and ICAM-1 levels $(\mathrm{P}<0.01)$ and with a less atherogenic lipid profile in addition to significant increase in level of HDL cholesterol by $12 \%(\mathrm{P}<0.05)$ and decreased uric acid levels by approximately $33 \%(\mathrm{P}=0.021)$ in overweight, non-smoking, older type 2 diabetic individuals ${ }^{41}$. However, Jilma and colleagues stated that after two different training protocols on an bicycle ergometer and endurance exercise in healthy untrained men at normal altitude have little influence on serum levels of the circulating vascular adhesion molecules ${ }^{42}$. Moreover, Link and colleagues investigated the systemic effect of physical training on the lower limbs, on the endothelial function of the radial artery in 22 men with congestive heart failure after one month, when compared to the control group ${ }^{43}$. Similarly, Payvandi and co-workers stated that increased levels of physical activity during daily life are associated with improved endothelial function in patients with peripheral arterial disease ${ }^{44}$.

The current study has important strengths and limitations. The major strength is the supervised nature of the study as all exercise sessions were supervised. In the other hand, the major limitations is only elderly subjects enrolled in the study, so the value of this study only related to this age group, also small sample size in the two groups may limit the possibility of generalization of the findings in the present study. Finally, within the limit of this study, aerobic exercise is more appropriate than resisted exercise in modulation of inflammatory and endothelial activation markers among elderly. Further researches are needed to explore the impact of exercise training on quality of life and other biochemical parameters among elderly.

\section{Acknowledgment}

This project was funded by the Deanship of Scientific Research (DSR) at King Abdulaziz University, Jeddah, under grant no. (G-12-290-1439). The authors, therefore, acknowledge with thanks DSR for technical and financial support.

\section{Conflict of interest}

None declared.

\section{References}

1. Santulli G, Iaccarino G. Pinpointing beta adrenergic recep-tor in ageing pathophysiology: victim or executioner? Evidence from crime scenes. Immun. Ageing 2013; 10:10.

2. Santulli G. Thrombolysis outcomes in acute ischemic stroke patients with prior stroke and diabetes mellitus. Neurology 2012; 78: 840.

3. Taddei S, Galetta F, Virdis A, Gheadoni L, Salvetti G, Franzoni F, et al. Physical activity prevents age-related 
impairment in nitric oxide availability in elderly athletes. Circulation 2000; 101(25): 2896-901.

4. Bruunsgaard H, Skinhoj P, Pedersen AN, Schroll M, Pedersen BK. Ageing, tumour necrosis factor-alpha (TNF-alpha) and atherosclerosis. Clin Exp Immunol 2000;121:255-260.

5. Toth MJ, Ades PA, Tischler MD, Tracy RP, LeWinter MM. Immune activation is associated with reduced skeletal muscle mass and physical function in chronic heart failure. Int J Cardiol 2006;109:179-187.

6. Allin KH, Nordestgaard BG, Zacho J, Tybjaerg-Hansen A, Bojesen SE. Creactive protein and the risk of cancer: a mendelian randomization study. J Natl Cancer Inst 2010; 102: 202-206.

7. Wensley F, Gao P, Burgess S, Kaptoge S, Di AE, Shah $\mathrm{T}$, Engert JC, et al. Association between $\mathrm{C}$ reactive protein and coronary heart disease: mendelian randomisation analysis based on individual participant data. BMJ 2011; $342, \mathrm{~d} 548$.

8. Dengel DR, Brown MD, Reynolds TH, Kuskowski MA, Supiano MA. Effect of aerobic exercise training on blood pressure sensitivity to dietary sodium in older hypertensives. J. Hum. Hypertens 2006; 20:372-378.

9. Nualnim N, Parkhurst K, Dhindsa M, Tarumi T, Vavrek $\mathrm{J}$, Tanaka $\mathrm{H}$. Effects of swimming training on blood pressure and vascular function in adults $>50$ years of age. $\mathrm{Am}$ J Cardiol 2012; 109:1005-1010.

10. Kapasi ZF, Ouslander JG, Schnelle JF, Kunter M, Fahey JL. Effects of an exercise intervention on immunologic parameters in frail elderly nursing home residents. $J$ Gerontol Med Sci 2003; 58:636-643.

11. Woods JA, Ceddia MA, Wolters BW, Evan JK, Mcauley E. Effects of 6 months of moderate aerobic exercise training on immune function in the elderly. Mech Ageing Dev 1999; 109:1-19 PubMed .

12. Ploeger HE, Takken T, de Greef MH, Timmons BW. The effects of acute and chronic exercise on inflammatory markers in children and adults with a chronic inflammatory disease: a systematic review. Exerc Immunol Rev 2009; 15:6-41.

13. Prestes J, Shiguemoto G, Botero JP. Effects of resistance training on resistin, leptin, cytokines, and muscle force in elderly post-menopausal women. J Sports Sci 2009; 27(14):1607-1615.

14. White LJ, Castellano V, McCoY SC. Cytokine responses to resistance training in people with multiple sclerosis. J. Sports Sci 2006; 24:911-914.
15. Pahkala K, Heinonen OJ, Lagström H. Vascular endothelial function and leisure-time physical activity in adolescents. Circulation 2008; 118: 2353-2359 PubMed .

16. Sugiyama T, Healy GN, Dunstan DW, Salmon J, Owen $\mathrm{N}$. Joint associations of multiple leisure-time sedentary behaviours and physical activity with obesity in Australian adults. Int J Behav Nutr Phys Act 2008; 5: 35.

17. Collier SR, Kanaley JA, Carhart R. Effect of 4 weeks of aerobic or resistance exercise training on arterial stiffness, blood flow and blood pressure in pre- and stage- 1 hypertensives. J Hum Hypertens 2008; 22: 678-686 PubMed. 18. DeSouza CA, Shapiro LF, Clevenger CM . Regular aerobic exercise prevents and restores age-related declines in endothelium-dependent vasodilation in healthy men. Circulation 2000;102:1351-1357.

19. Robergs RA, Landwehr R. The surprising history of the "HRmax=220-age" equation. I Exerc Physiol Online 2002; 5(2):1-10.

20. Ramalho AC, de Lourdes Lima M, Nunes F, Cambuí Z, Barbosa C, Andrade A, Viana A, Martins M, Abrantes V, Aragão C, Temístocles M. The effect of resistance versus aerobic training on metabolic control in patients with type-1 diabetes mellitus. Diabetes Res Clin Pract 2006; 72(3):271-6.

21. Cartier A., C`ot'e M., Lemieux I. Age-related differences in inflammatory markers in men: contribution of visceral adiposity. Metabolism 2009;58:1452-1458.

22. Devaux B, Scholz D, Hirche A, Klovekorn WP, Schaper J. Upregulation of cell adhesion molecules and the presence of low grade inflammation in human chronic heart failure. European Heart Journal 1997; 18:470-479.

23. Donges CE, Duffield R, Drinkwater EJ. Effects of resistance or aerobic exercise training on interleukin-6, C - reactive protein, and body composition. Med Sci Sports Exerc 2010; 42:304-313.

24. Balducci S, Zanuso S, Nicolucci A. Anti-inflammatory effect of exercise training in subjects with type 2 diabetes and the metabolic syndrome is dependent on exercise modalities and independent of weight loss. Nutr Metab Cardiovasc Dis 2010; 20:608-617.

25. Libardi CA, Souza GV, Cavaglieri CR. Effect of resistance, endurance, and concurrent training on TNF-a, IL-6, and CRP. Med Sci Sports Exerc 2012; 44:50-56.

26. Geffken DF, Cushman M, Burke GL, Polak JF, Sakkinen PA, Tracy RP. Association between physical activity and markers of inflammation in a healthy elderly population. Am J Epidemiol 2001;153:242-250. 
27. Colbert LH, Visser M, Simonsick EM, Tracy RP, Newman AB, Kritchevsky SB, Pahor M, Taaffe DR, Brach J, Rubin S, Harris TB. Physical activity, exercise, and inflammatory markers in older adults: findings from the Health, Aging and Body Composition Study. J Am Geriatr Soc 2004;52:1098-1104.

28. Yu Z, Ye X, Wang J, Qi Q, Franco OH, Rennie KL, Pan A, Li H, Liu Y, Hu FB, Lin X. Associations of physical activity with inflammatory factors, adipocytokines, and metabolic syndrome in middle-aged and older Chinese people. Circulation 2009;119:2969-2977.

29. Nicklas BJ, Hsu FC, Brinkley TJ, Church T, Goodpaster BH, Kritchevsky SB, Pahor M. Exercise training and plasma C-reactive protein and interleukin- 6 in elderly people. J Am Geriatr Soc 2008;56:2045-2052.

30. Santos R, Viana V, Boscolo R, Marques V, Santana M, Lira F, Tufik S, de Mello M. Moderate exercise training modulates cytokine profile and sleep in elderly people. Cytokine 2012;60:731-735.

31. Kohut ML, McCann DA, Russell DW, Konopka DN, Cunnick JE, Franke WD, Vanderah E. Aerobic exercise, but not flexibility/resistance exercise, reduces serum IL18, CRP, and IL-6 independent of beta-blockers, BMI, and psychosocial factors in older adults. Brain Behav Immun 2006;20 (3):201-209.

32. Bote ME, Garcia JJ, Hinchado MD, Ortega E. An exploratory study of the effect of regular aquatic exercise on the function of neutrophils from women with fibromyalgia: role of IL-8 and noradrenaline. Brain Behav. Brain Behav Immun 2014;39:107-12 PubMed

33. White LJ, Castellano V, McCoY SC. Cytokine responses to resistance training in people with multiple sclerosis. J. Sports Sci 2006; 24:911-914.

34. Prestes J, Shiguemoto G, Botero JP. Effects of resistance training on resistin, leptin, cytokines, and muscle force in elderly post-menopausal women. J Sports Sci 2009; 27(14):1607-1615.

35. Ploeger HE, Takken T, de Greef MH, Timmons BW. The effects of acute and chronic exercise on inflammato- ry markers in children and adults with a chronic inflammatory disease: a systematic review. Exerc Immunol Rev 2009; 15:6-41.

36. Mathur M, Pedersen B. Exercise as a mean to control low-grade inflammation. Mediators Inflamm 2008; 2008:109502.

37. Timmerman K, Flynn M, Coen P, Markofski M , Pence B. Exercise training-induced lowering of inflammatory $(\mathrm{CD} 14+\mathrm{CD} 16+)$ monocytes: a role in the anti-inflammatory influence of exercise? Leukoc Biol 2008; 84: 1271-1278 PubMed .

38. Wang J, Song H, Tang X, Yang Y, Vieira VJ, Niu Y, Ma Y. Effect of exercise training intensity on murine $T$ regulatory cells and vaccination response. Scand J Med Sci Sports 2012; 22(5):643-52.

39. Hong S, Dimitrov S, Pruitt C, Shaikh F, Beg N. Benefit of physical fitness against inflammation in obesity: role of beta adrenergic receptors. Brain Behav Immun. 2014;39:113-20.

40. Yang AL, Chen HI, Yang AL, Chen HI. Chronic exercise reduces adhesion molecules/iNOS expression and partially reverses vascular responsiveness in hypercholesterolemic rabbit aortae. Atherosclerosis 2003; 169(1):11-7.

41. Zoppini G1, Targher G, Zamboni C, Venturi C, Cacciatori V, Moghetti P, Muggeo M. Effects of moderate-intensity exercise training on plasma biomarkers of inflammation and endothelial dysfunction in older patients with type 2 diabetes. Nutr Metab Cardiovasc Dis 2006; 16(8):5439.

42. Jilma B, Eichler HG, Stohlawetz P, Dirnberger E, Kapiotis S, Wagner O, Schütz W, Krejcy K. Effects of exercise on circulating vascular adhesion molecules in healthy men. Immunobiology 1997; 197(5):505-12.

43. Link A, Schoence N, Gielen S, Hofer J, Erbs S, Schuler G. Endothelial dysfunction in patients with chronic heart failure: systemic effects of lower-limb exercise training. $J$ Am Coll Cardiol 2001; 37 (2): 392-7.

44. Payvandi L, Dyer A, McPherson D. Physical activity during daily life and brachial artery flow-mediated dilation in peripheral arterial disease. Vasc Med 2009; 14: 193-201. 